\title{
OS ASPECTOS CULTURAIS NA ELABORAÇÃO DE MATERIAL DIDÁTICO PARA O ENSINO DE LÍNGUA DE HERANÇA: ESTUDO DE CASO
}

\author{
LOS ASPECTOS CULTURALES EN LA ELABORACIÓN DE MATERIAL \\ DIDÁCTICO PARA LA ENSEÑANZA DE LENGUA DE HERENCIA: UN \\ ESTUDIO DE CASO
}
THE CULTURAL ASPECTS IN THE ELABORATION OF TEACHING MATERIAL FOR THE TEACHING OF HERITAGE LANGUAGE: A CASE STUDY

\author{
Rosângela Maria Laurindo FORNASIER ${ }^{1}$ \\ Fernanda Landucci ORTALE ${ }^{2}$ \\ Vinicio CORRIAS ${ }^{3}$
}

RESUMO: Neste artigo são apresentadas as principais contribuições de um estudo sobre o papel da cultura na elaboração de materiais didáticos em contexto de ensino de italiano como língua de herança. Como base teórica foram utilizados os pressupostos da Pedagogia Pós-Método, bem como os conceitos de cultura, identidade e língua de herança. Os resultados apontam, em primeiro lugar, que histórias de vida de membros da comunidade podem se constituir como uma rica matéria-prima para elaboração de material didático e, em segundo lugar, que o próprio ato de colher narrativas orais na língua de herança contribui para que a própria comunidade se envolva no planejamento de ações para a revitalização linguística e cultural de que são herdeiros.

PALAVRAS-CHAVE: Língua de herança. Imigração italiana. Pedagogia pós-método.

RESUMEN: En este artículo se presentan las principales contribuciones de un estudio acerca del papel de la cultura en la elaboración de materiales didácticos en contexto de enseñanza de italiano como lengua de herencia. Como base teórica se utilizaron los presupuestos de la Pedagogía post-método, así como los conceptos de cultura, identidad y lengua de herencia. Los resultados muestran, en primer lugar, que las historias de vida de miembros de la comunidad pueden constituir una bella materia prima para la elaboración de material didáctico y, en según lugar, que el propio acto de elegir narrativas orales en lengua de herencia contribuyen para que la propia comunidad se involucre en la planificación de acciones hacia la revitalización lingüística y cultural de que son herederos.

\footnotetext{
${ }^{1}$ Universidade de São Paulo (USP), São Paulo - SP - Brasil. Doutoranda em Língua, Literatura e Cultura Italianas. Departamento de Letras Modernas da USP/SP. ORCID: <https://orcid.org/0000-0003-41192910>. E-mail: rosangelamaria_romaria@yahoo.com.br

${ }^{2}$ Universidade de São Paulo (USP), São Paulo - SP - Brasil. Docente do Departamento de Letras Modernas. Livre-docente em Língua Literatura e Cultura Italianas pelas USP/SP. ORCID: <https://orcid.org/0000-0002-9095-6262>.E-mail: ortale@usp.br

${ }^{3}$ Universidade de São Paulo (USP), São Paulo - SP - Brasil. Doutorando pela USP/SP na área de Língua, Literatura e Cultura Italianas. Departamento de Letras Modernas da USP/SP. ORCID: <https://orcid.org/0000-0001-7518-9037>.E-mail: viniciocorrias@usp.br
} 
PALABRAS CLAVE: Lengua de herencia. Inmigración italiana. Pedagogía postmétodo.

ABSTRACT: This article presents a study about the planning and implementation of an Italian language course as a Heritage Language (HL). The theoretical basis of this research is based on Post-Method Pedagogy, Oral History Methodology and Heritage Language studies. Preliminary results point to the need to create more formal language teaching spaces, as well as to the importance of familiar linguistic policies for their maintenance in informal contexts. The work also corroborates the idea that the teaching of language of inheritance is distinguished from teaching of foreign language, due to the specificities of the revitalization of language and culture.

KEYWORDS: Heritage language. Italian immigration. Post-method pedagogy.

\section{Introdução}

Este artigo apresenta uma discussão sobre a presença de aspectos culturais nas histórias de vida de imigrantes e, portanto, dessas narrativas como principal recurso na elaboração do material didático para um curso de italiano como língua de herança (LH doravante).

Trata-se de um estudo de caso realizado durante o período de agosto de 2015 a dezembro de 2017, na ex-colônia italiana de Pedrinhas Paulista. A cidade teve origem em um dos últimos movimentos migratórios ocorridos no pós-guerra, em 1952, por meio de um acordo feito entre o Brasil e a Itália, em 08/10/1947, mantendo-se na condição de colônia até 14/05/1980, quando recebeu o status de Distrito, obtendo sua emancipação político-administrativa em 30/12/1991. Em 1949, o Governo Italiano enviou técnicos por meio da Missão Técnica Agrícola para efetuar estudos de reconhecimento territorial e de fertilidade em áreas rurais de inúmeros países da América do Sul. No Brasil, foram selecionadas as cidades de São Geraldo (GO), Joinville (SC) e Pedrinhas Paulista (SP). Dentre elas, a única colônia que obteve sucesso, supostamente em razão da fertilidade das terras do Vale do Paranapanema, foi a de Pedrinhas Paulista (BORGES PEREIRA, 2002, p. 47).

O transporte das famílias italianas para Pedrinhas Paulista foi realizado pela Companhia Brasileira de Colonização e Imigração Italiana, regulamentada pelo Decreto-Lei $n^{\circ}$ 7.967, promulgado em 1945. Esse processo de imigração deu-se de forma diferente daquele ocorrido no início do século $\mathrm{XX}$, pois os imigrantes que chegaram ao Brasil, em 1952, receberam condições e assistência para trabalhar as terras 
que lhes foram conferidas, produzir e prosperar. A Companhia, que permaneceu no local até 1984, por meio do trabalho de técnicos e engenheiros italianos, planejou a colonização, dotando os lotes de terra com infraestrutura mínima (construindo casa de alvenaria com banheiro fora, cocheira, galinheiro, poço de água, local para armazenar a colheita; oferecendo animais como boi, vacas, porcos, galinhas para criação e próprio consumo). Os italianos puderam pagar o lote de terra recebido em dez parcelas anuais.

Após sua fundação, em 21 de setembro de 1952, a colônia de Pedrinhas Paulista recebeu um grupo inicial de imigrantes italianos, constituído por 28 famílias, oriundas de diversas regiões da Itália. Nos anos seguintes, outros imigrantes desembarcaram em direção à colônia, totalizando 236 famílias de imigrantes até 1968 (BORGES PEREIRA, 2002, p. 55).

O processo de escolarização e a convivência com os brasileiros, por meio de práticas sociais cotidianas, ocasionaram a aquisição do português por parte dos imigrantes e de seus filhos, que, com o tempo, passaram a ter o português como língua de domínio. Atualmente, as famílias desta comunidade são constituídas por meio da união de descendentes de italianos com pessoas de diversas origens e as línguas faladas são o português, o italiano e a variedade ítalo-pedrinhense (CASTRO, 2002, s/p).

Traços das identidades brasileira e italiana são facilmente notados no município, desde o seu portal de entrada, onde tremulam lado a lado as bandeiras do Brasil e da Itália; nas praças principais da cidade (Praça Roma e Praça Monsenhor Ernesto Montagner) com a presença das estátuas de Rômulo e Remo e também de centuriões romanos, com os memoriais ao imigrante italiano e aos brasileiros pioneiros; nos nomes que levam as duas avenidas principais que se cruzam - Brasil e Itália. Nas praças da cidade, a língua italiana ainda está presente nas conversas entre os imigrantes e alguns dialetos ainda são falados em núcleos familiares. Muito da cultura italiana pode ser observada na comunidade - como o hábito de fazer massas caseiras, o vinho artesanal, salame e copa, as danças típicas, a arquitetura greco-romana em prédios públicos. Podese observar, portanto, que a cidade apresenta uma identidade intercultural que se reflete ainda hoje na língua, nos hábitos, nas tradições da comunidade e em seu espaço arquitetônico.

Segundo Ortale, Corrias e Fornasier (2017, p. 73):

A comunidade de Pedrinhas Paulista criou para si um 'terceiro espaço' (LO BIANCO; LIDDICOAT; CROZET, 1999, p. 5), constituído por um quadro de referências ligado às suas origens culturais italianas, mas também, pelas referências culturais e linguísticas dos brasileiros. 
Apesar de ainda estarem presentes tantos elementos culturais e linguísticos na comunidade, observa-se, contudo, um movimento progressivo de perda da língua italiana e dos dialetos, pois os imigrantes que hoje estão com idades entre 70 e 90 anos, em sua maioria, ainda falam o italiano e/ou o dialeto de sua região com seus filhos. Porém, membros da primeira geração nascida no Brasil não interagem cotidianamente em italiano ou dialeto com seus filhos. A quebra da transmissão da LH como parte da cultura familiar ocorreu nesse espaço intergeracional e é nele que concentramos nossos estudos, com o escopo de manter e revitalizar a língua e a cultura italiana nessa ex-colônia. Motivados por essa perda linguístico-cultural, decidimos nos ativar para impedi-la. Como primeiro passo, foi necessário entender o que era uma LH, para poder criar nosso sentido desse termo.

\section{As histórias de vida como portadoras de cultura no contexto de LH}

A expressão "língua de herança" teve origem no Canadá nos anos 70 e passou a ser alvo de estudos nos EUA nos anos 90 (SOARES, 2012, p. 8), o que nos permite inferir que se trata de uma área de estudos ainda recente. Segundo Mendes (2012), a LH é uma língua transmitida, de modo formal ou informal, por pais imigrantes - que a tem como língua materna - a seus filhos que cresceram no exterior. Eventualmente, a LH chega aos descendentes das gerações seguintes, embora, como veremos mais adiante, isso nem sempre ocorra, sobretudo em nível linguístico, sendo mais comum em nível cultural. A LH se distingue de uma língua estrangeira (LE) e também não pode ser definida como língua materna.

Movimentos migratórios sempre ocorreram no mundo pelas mais diversas razões e a manutenção da língua e da cultura do país de origem constitui um dos grandes desafios enfrentados por esses indivíduos que deixam seus países e se estabelecem no exterior, uma vez que seus filhos, no momento em que vão para a escola, acabam por abandonar o uso da LH, passando a usar em tempo quase que integral a língua do país que os acolheu e, em pouco tempo, esta passa a ser sua língua de domínio (SOUZA; BARRADAS, 2013). Esse fato também ocorreu na ex-colônia de Pedrinhas Paulista, conforme citado na introdução deste artigo. Assim como a apropriação da língua e da cultura do país de acolhida ocorreu, deu-se também o contrário: muitos indivíduos de origem brasileira também se identificaram com a língua e com a cultura italianas, o que nos permite dizer que esta é uma comunidade de cultura híbrida. 
Por essa razão, em nosso contexto de pesquisa, adotamos um conceito de LH que não está necessariamente vinculado ao fator de ancestralidade, de Ortale (2016, p. 27):

Língua de herança é a língua com a qual uma pessoa possui identificação cultural e sentimento de pertencimento a determinada comunidade que a usa, seja por laços ancestrais, seja por convivência no mesmo ambiente sociocultural com falantes dessa língua.

Acreditamos que o italiano pode ser considerado uma LH para os habitantes de Pedrinhas Paulista que possuem ou não origem italiana, uma vez que não só os descendentes como também seus cônjuges e outras pessoas da comunidade de origem não italiana estão expostos a essa língua e cultura, podendo ocorrer uma identificação com ambas. O parâmetro central para a adoção dessa definição de LH é, portanto, o sentimento de autopercepção identitária em relação à língua e à cultura de determinado país, neste caso a Itália.

Esse conceito nos permite analisar a relação que a comunidade de Pedrinhas Paulista estabelece com a língua italiana e o papel da cultura no ensino de LH, de modo que contribua para a (re)construção das identidades culturais dos aprendizes.

Segundo o antropólogo Edward T. Hall (1990, p. 20), “cultura representa o modo de viver das pessoas, como a soma dos padrões de comportamento aprendidos, atitudes e coisas materiais". Samovar, Porter e McDaniel (2010, p. 12) afirmam que a cultura é aprendida a partir do nascimento, quando começamos a assimilar as regras sociais necessárias para efetivamente funcionarmos em nossa cultura. Essa aprendizagem se dá por meio da interação, observação e imitação. Comer com um par de pauzinhos, com os dedos ou com um garfo, por exemplo, é um comportamento cultural que se aprende. Os autores dizem ainda que os símbolos que utilizamos para nos comunicar - palavras, gestos e imagens - são elementos culturais por meio dos quais transmitimos para as próximas gerações comportamentos e valores, que podem, ao longo do tempo, modifica-se ou novos valores podem ser construídos, mas é o acúmulo de tradições passadas que conhecemos como cultura. Por possuir esse caráter dinâmico, a cultura está em constante processo de transformação e o advento da internet acelerou esse processo, tornando a difusão das culturas ainda mais fácil.

Ampliando ainda mais a noção de cultura, o sociólogo jamaicano Stuart Hall diz que indivíduos pertencentes a uma mesma cultura interpretam o mundo e expressam seus sentimentos de modo reciprocamente compatível. 
A cultura, como a discutimos, não é um conjunto de coisas - livros, pinturas, programas de TV ou histórias em quadrinhos - mas um processo ou um conjunto de práticas. A cultura se refere, principalmente, à produção e troca de significados entre os membros de uma sociedade ou grupo. Afirmar que duas pessoas pertencem à mesma cultura significa dizer que elas, de modo geral, interpretam o mundo e podem expressar seus pensamentos e sentimentos sobre o mundo de modo semelhante (HALL, 1997, p. 2).

Mendes (2015) reflete sobre a gênese do conceito de cultura, discorrendo desde a evolução do sentido da palavra, passando pelo surgimento do primeiro conceito e sua evolução em algumas áreas do conhecimento. No campo do ensino/aprendizagem de LE, a autora afirma que:

A cultura, na maior parte dos livros didáticos de português língua estrangeira (PLE) ou segunda língua (PL2), por exemplo, aparece como ilustração, como conteúdo a ser ensinado, sobretudo dando-se destaque para aquilo que, no imaginário comum, representaria a riqueza cultural de um povo, como a culinária, as festas populares, as tradições, o comportamento etc. A língua, desse modo, é vista apenas como um sistema que está a serviço da transmissão cultural, passada de geração a geração, de modo uniforme e estático. (MENDES, 2015, p. 208).

A reflexão feita por Mendes de que a cultura ensinada nos livros didáticos de PLE e PL2 aparece apenas como ilustração ou como um conteúdo a ser ensinado - o que restringe o seu significado - vem ao encontro daquilo que acreditamos, pois compreendemos que o ensino da cultura vai além da utilização de elementos culturais como culinária, festas, tradições e comportamentos, ele agrega ainda o modo de pensar de um povo, como age, compreende o mundo e como significa na língua (HALL, 1997). A língua não é apenas um instrumento de transmissão da cultura, mas também um elemento que a integra. Neste sentido, o trabalho com as histórias de vida dos imigrantes italianos no curso de LH configura-se como elemento fundamental, uma vez que trazem para os aprendizes elementos culturais altamente relevantes, permitem que os alunos possam observar o modo como eles significam em língua italiana e como compreendem o mundo e a própria história, contribuindo ainda para a (re)construção de suas identidades.

Os conceitos de identidade adotados nesta reflexão são aqueles propostos por Bauman (2003) e Hall (2005). Hall afirma que, com o processo de globalização, a construção da identidade do sujeito pós-moderno se dá pela interação com os outros à sua volta, sendo capaz de examinar e refletir tais práticas sociais e, portanto, de escolher 
com quais delas se identifica e quais delas tomará para si. Bauman também aponta para esse fato afirmando que, na modernidade-líquida, o sujeito se encontra diante de tantas ideias e princípios que acredita ser necessário comparar, fazer escolhas e reconsiderá-las em outras ocasiões. Acreditamos que as histórias de vida dos imigrantes possam contribuir significativamente não só para o desenvolvimento da competência comunicativa dos aprendizes, como insumo linguístico, mas também contribuam para a (re)construção da suas identidades, uma vez que não é fixa e definitiva, e sim dinâmica, assim como a cultura, que com o passar do tempo pode modificar-se (SAMOVAR; PORTER; MC DANIEL, 2010).

\section{Elaborando materiais para o ensino de LH: os caminhos de um processo}

Estudos sobre LH evidenciaram que esse contexto "exige especificidades quanto aos materiais didáticos, ferramentas de avaliação, formação de professores" (ORTALE, 2017, p. 15). Para tanto, foi criado um grupo de pesquisa para o planejamento, produção do material didático e implementação do curso Italiano como Herança. Ele partiu dos pressupostos teóricos de Kumaravadivelu, autor da Pedagogia Pós-Método (2001, 2003, 2006), e de Leffa (2016). Esse último propõe em seus estudos as fases essenciais que envolvem a produção de materiais didáticos - sendo elas análise, desenvolvimento, implementação e avaliação, enquanto Kumaravadivelu propõe três princípios norteadores do processo de ensino-aprendizagem de línguas.

Para a produção do material didático, de acordo com Leffa (2016), a fase de análise compreende uma investigação atenta do público-alvo. Cientes do fato de que a quebra na transmissão da língua se dá no espaço intergeracional dos filhos para os netos de imigrantes, determinamos que o curso fosse oferecido a membros da primeira geração nascida no Brasil e seus cônjuges. A ideia de oferecer também aos cônjuges, embora muitos não fossem descendentes, era a de que o italiano seria também para eles uma LH, por estarem imersos na cultura há muitos anos. Além de determinarmos a faixa etária dos alunos, que estaria entre os 40 e 60 anos, investigamos também o nível de adiantamento de cada aluno na língua-alvo, suas necessidades e expectativas em relação ao curso. (LEFFA, 2016, p. 105). Para esse fim, incluímos um questionário na ficha de matrícula dos alunos.

A fase de análise proposta por Leffa (2016) pressupõe uma análise que antecede a produção do material didático. Para este trabalho, pautado também nos pressupostos 
da Pedagogia Pós-Método, de Kumaravadivelu (2003, 2006), a fase de análise se estendeu por toda a fase de implementação do curso e, inevitavelmente, acabou por se entrelaçar com a fase de avaliação, já que o material didático foi elaborado durante o curso, com base nas respostas dos alunos às atividades e conteúdos propostos e com base em nossas reflexões sobre o andamento das aulas.

A escolha da abordagem de ensino foi o próximo passo para o desenvolvimento do material didático. Almeida Filho (2002, p. 13) define abordagem de ensino como "uma espécie de filosofia, uma força potencial capaz de orientar todas as decisões e ações da operação global de ensinar línguas". Como o objetivo geral para o curso Italiano como Herança é o de desenvolver a competência comunicativa dos alunos por meio de temas sobre a cultura, tendo o ouvir e o falar como as principais habilidades, mas não deixando de usar as de ler e escrever, adotamos uma das abordagens de ensino propostas por Leffa (2016), a Abordagem baseada em conteúdo, cuja ênfase está no conteúdo, usando a língua que o aluno precisa aprender, pressupondo-se que enquanto o aluno presta atenção no conteúdo, acaba adquirindo a língua incidentalmente. $\mathrm{O}$ material, portanto, não é desenvolvido a partir de tópicos gramaticais, mas sim de tópicos do próprio conteúdo, os quais, neste caso, giraram em torno de elementos que compõem a cultura italiana e a história da comunidade de Pedrinhas Paulista.

Após definirmos os temas de cada unidade didática - a Imigração italiana no mundo e a história dos imigrantes de Pedrinhas Paulista; a imigração na Itália atual; a alimentação na Itália e a história da língua italiana e os dialetos - passamos a colher material junto à comunidade para a elaboração das atividades que o comporiam. Conseguimos os mais variados tipos de textos: relatos pessoais escritos, entrevistas em vídeo, cartas, poemas, textos de memórias, textos produzidos a partir de entrevistas e fotografias. Além do material doado pela comunidade, utilizamos também crônicas, notícias de jornal, vídeos da internet, mapas, trechos de filmes e de shows, entre outros, sendo todos textos autênticos e sempre ligados ao tema proposto.

$\mathrm{O}$ material coletado foi didatizado e introduzido no material do curso de $\mathrm{LH}$, compondo atividades frequentemente interativas como diálogos, discussões, produções orais com base em tarefas, tendo em vista que o curso foi estruturado embasando-se na Abordagem Comunicativa (SCALZO, 1998), razão pela qual o uso da gramática foi deixado em segundo plano, para quando fosse necessário. Ao final de cada unidade didática oferecemos uma canção relacionada ao tema proposto, pois entendemos que a 
música faz parte da bagagem cultural de um povo e, por meio dela, expressam seus sentimentos, histórias e visões de mundo.

A implementação do material ocorreu de modo intuitivo (LEFFA, 2016), isto é, possíveis lacunas deixadas no material puderam ser completadas oralmente, durante a aplicação das atividades, garantindo, assim, uma maior produtividade. Para Leffa (2016, p. 34) esse tipo de implementação dá-se quando o autor do material é também o professor que vai usar esse material junto com os alunos em sala de aula.

Um aspecto importante da implementação do material durante o curso de italiano LH de Pedrinhas Paulista foi o uso de histórias de vida relativas ao período de chegada dos primeiros imigrantes. A fundação de Pedrinhas remonta ao 1952 e vários dos protagonistas dessa fundação ainda estão vivos e participaram do curso, através de escritos, vídeos e até pessoalmente, intervindo em algumas aulas e sendo entrevistados pelos alunos do curso. Enquanto a maioria desses relatos e vídeos foi incluída já na fase de desenvolvimento do material, as entrevistas foram gravadas com o objetivo de usálas como material didático em outros cursos de italiano LH em Pedrinhas Paulista e também para serem incluídas no patrimônio cultural da cidade.

A avaliação do material didático foi contínua e, conforme já dito, foi concomitante ao processo de análise e implementação. Conforme o material era aplicado, observávamos se as atividades eram bem executadas pelos alunos, se despertavam o seu interesse e se conseguíamos atingir os objetivos propostos. Além do nosso olhar atento e reflexivo, utilizamos ainda alguns questionários ao final das aulas, de modo anônimo para garantir maior fidelidade das impressões dos alunos sobre as atividades propostas no material. Essas ferramentas nos permitiram observar o quanto eles gostavam do trabalho com as histórias de vida, das visitas dos imigrantes ao final de cada unidade temática para a partilha suas experiências e o quanto consideraram importante o resgate desse patrimônio histórico-cultural.

Foi por meio do trabalho com o conteúdo, através das histórias de vida dos imigrantes, que os alunos, sem se darem conta, ao estudá-los, foram adquirindo a língua italiana, ou aprimorando o que já sabiam. Observamos melhora na pronúncia, no uso de algumas estruturas linguísticas e um aumento no léxico daqueles que já sabiam um pouco da língua; e uma melhora no nível de compreensão oral daqueles que compreendiam pouco e algum avanço na produção oral. O que se deu de modo similar 
para todos foi a aquisição de um conteúdo cultural muito rico e importante para a (re)construção ${ }^{4}$ da identidade de cada um.

\section{Aspectos culturais no ensino de LH: a produção do material didático na perspectiva Pós-Método}

A pedagogia Pós-Método fundamenta esta pesquisa por entendermos que para o ensino de LH é necessária uma postura reflexiva do professor, que passa a ser produtor das próprias teorias e autor da própria prática de ensino, adequando-as ao público-alvo, a partir dos objetivos propostos. $\mathrm{O}$ autor propõe um sistema tridimensional que define a Pedagogia Pós-Método, são eles: o parâmetro da particularidade, o parâmetro da praticidade e o parâmetro da possibilidade (KUMARAVADIVELU, 2003, 2006).

O parâmetro da particularidade aborda a importância de a pedagogia de línguas ser sensível às particularidades do contexto da instituição e do ambiente sociocultural, bem como ao grupo específico de alunos e professores. Esse parâmetro compreende ainda a importância da observação e reflexão do professor sobre suas ações em sala de aula e sobre os resultados obtidos.

O parâmetro da praticidade compreende uma relação dialógica entre teoria e prática. Ele propõe que professor deve ser o produtor de teorias, pondo-as posteriormente em prática, mas também, o contrário, deve gerar teorias a partir de suas práticas.

O parâmetro da possibilidade ressalta a necessidade de ações que possibilitem transformações sociais, levando-se em conta ainda a identidade e as experiências trazidas pelos alunos.

Os três parâmetros da Pedagogia Pós-Método, de Kumaravadivelu, permearam todo o processo de concepção do curso Italiano como Herança, os quais serão discutidos a seguir.

\section{O parâmetro da particularidade no ensino da cultura no curso de LH}

A decisão de fazermos uso da Abordagem Baseada em Conteúdos (LEFFA, 2016) no material didático para o curso de LH e da Abordagem Comunicativa

\footnotetext{
4 A (re)construção da identidade baseia-se em Bauman (2005): na era líquido-moderna, tanto a "identidade" quanto o "pertencimento" não estão garantidos por toda a vida e a identidade está em constante (re)construção, pela exposição a determinadas culturas ou por nossas escolhas.
} 
(SCALZO, 1998) em sala de aula foi tomada à luz do parâmetro da particularidade da Pedagogia Pós-Método (KUMARAVADIVELU, 2003).

O trabalho com eixos temáticos facilitou a inclusão do contexto sociocultural da comunidade no material. O primeiro módulo foi composto pelos seguintes temas: a grande imigração italiana; os fluxos migratórios que atingem a Itália atual; os hábitos alimentares do italiano; a história da língua italiana. (FORNASIER, 2018)

Para a elaboração do material, iniciamos, junto à comunidade, a coleta de materiais que pudessem oferecer insumo linguístico para o desenvolvimento das unidades didáticas. Realizamos entrevistas gravadas em vídeo, durante o período de julho/2015 a julho/2016, com os italianos que chegaram a Pedrinhas Paulista na ocasião da fundação da colônia, com a primeira geração nascida no Brasil e também com pessoas que tiveram participação política na vida da comunidade.

As entrevistas tinham como temas as memórias dos imigrantes sobre a vida na Itália, as consequências sofridas pela Segunda Guerra Mundial e informações sobre a partida para o Brasil, a chegada a Pedrinhas Paulista e as línguas ou dialetos falados pelos imigrantes no âmbito familiar. Essas entrevistas passaram a compor o material didático do curso de LH após serem didatizadas, por meio de um processo de edição, de acordo com as necessidades de cada unidade. Outros materiais foram oferecidos pela comunidade: cartas, diários, relatos de memórias, poemas, cadernos de receitas, documentos e fotografias de família, que também compuseram o material didático elaborado.

O trabalho com textos coletados junto à própria comunidade, por meio de suas histórias de vida (MEYHI; HOLANDA, 2015), propiciou o contato dos alunos com elementos da cultura italiana e ítalo-pedrinhense, o que oportunizou não só o acesso frequente a um insumo linguístico autêntico, contribuindo para a evolução da competência comunicativa dos mesmos, como também contribuiu para a (re)construção de suas identidades culturais (BAUMAN, 2005).

\section{O parâmetro da praticidade na postura da professora/pesquisadora e do grupo de pesquisa}

O desafio de conceber um curso de LH - cujos objetivos são desenvolver a competência comunicativa dos alunos e auxiliá-los na (re)construção de suas identidades culturais, contribuindo assim para a revitalização e manutenção da língua e 
da cultura italiana -, exigiu de nosso grupo de pesquisa maior atenção às teorias adotadas para alcançá-los. Foi necessária uma postura reflexiva da professora/pesquisadora, bem como de todo o grupo de pesquisa, para a escolha das abordagens de ensino tanto para a produção do material didático como para o seu uso em sala de aula.

Por essa razão optamos por iniciar o curso com apenas uma unidade didática pronta, as demais foram produzidas no decorrer do curso, pautados em nossas observações e reflexões sobre o desenvolvimento das atividades em sala de aula e nas necessidades dos alunos. Muitos foram os desafios que exigiram de nosso grupo de pesquisa reflexão, estabelecendo a relação dialógica necessária entre teoria e prática para o sucesso do curso.

Isso foi também devido à necessidade de analisar não apenas as necessidades objetivas dos alunos, o que foi feito antes do começo do curso, através de questionários, mas também aquelas subjetivas. As necessidades subjetivas, isto é, coisas de que (não) se gosta, desejos, expectativas e podem ser diagnosticadas apenas com a cooperação e participação ativas dos aprendizes (KUMARAVADIVELU, 2012, p. 39). Em nossa opinião, uma análise desse tipo era possível apenas após um contato com os aprendizes que só podia se dar em sala de aula.

Alguns dos desafios enfrentados foram: a heterogeneidade da turma, que para um curso de LH é fundamental, mas que demandou muitas mudanças de estratégias de ensino, já que os níveis de proficiência em LH eram os mais variados; o receio de muitos alunos em se arriscaram a falar, conscientizando-os de que por meio de nosso sistema interlíngua (BORNETO, 1998) construímos hipóteses sobre a nova língua e conseguimos aprendê-la e que o erro é parte do processo de aprendizagem; fazer com que alguns alunos, habituados às abordagens estruturalistas de ensino, compreendessem que a abordagem comunicativa era a melhor escolha, pois o conhecimento da estrutura da língua por si só não garante a competência comunicativa.

\section{O parâmetro da possiblidade na tomada de consciência da comunidade e do município no tocante à preservação da cultura e da $\mathbf{L H}$}

Um dos objetivos do projeto de pesquisa, além de contribuir para o desenvolvimento da competência comunicativa e a manutenção da cultura italiana no 
município de Pedrinhas Paulista, foi ainda de que a comunidade e o município dessem continuidade a esse trabalho, propondo novas ações didáticas e políticas em prol da LH.

As habilidades linguísticas essenciais à comunicação não devem ser tomadas como única necessidade dos aprendizes, devemos nos atentar ainda à sua motivação e autonomia, observando as dimensões afetiva, ideológica e política do contexto de ensino, tendo em vista as potencialidades emancipatórias de um curso de línguas (KUMARAVADIVELU, 2012, p. 39-49).

Nesse sentido, nossos objetivos também foram atingidos, pois conseguimos despertar nos aprendizes o senso de responsabilidade no que se refere à preservação de traços da língua e da cultura. Hoje os alunos se preocupam com o registro das histórias de vida dos colonos para que se perpetuem pelas gerações vindouras e estão empenhados em resgatar e manter muitos costumes e tradições familiares, além de se esforçarem em utilizar a língua italiana e dialeto de suas regiões de origem em contexto familiar. Conseguimos também o auxílio do município para o curso de LH, que se responsabilizou pela impressão do material didático e ofereceu o Centro Cultural da cidade para a ministração das aulas. O município fez ainda uma proposta para a professora/pesquisadora de concepção de um curso de cultura italiana e brasileira para ser ministrado a alunos da EMEF.

O projeto Italiano como Herança foi o primeiro passo dado em favor da revitalização e manutenção da língua e traços da cultura italiana no município de Pedrinhas Paulista/SP, contudo, muito ainda tem que ser feito: notamos ainda a necessidade da formação de novos professores de $\mathrm{LH}$, membros da comunidade assim como a professora/pesquisadora, para a criação de novas turmas de LH que contemplem outras faixas etárias. Consideramos que os professores de LH devam ser membros da própria comunidade, pois estando inseridos nesse contexto, conhecem a fundo as necessidades dos alunos e da comunidade e também se identificam com a cultura e a $\mathrm{LH}$, o que contribui ainda mais com a riqueza dos elementos culturais contidos nas histórias de vida. Essa mobilização da comunidade é parte essencial desse processo, uma vez que:

A perda da história e da língua italiana nas famílias de descendentes dos fundadores da colônia, certamente, representariam o silenciamento de parte da identidade ítalopedrinhese presente na comunidade. (ORTALE, CORRIAS, FORNASIER, 2017, p. 82) 
O papel de nosso grupo de pesquisa nesse processo de resgate e preservação de traços da cultura italiana e ítalo-pedrinhense e do italiano como LH é dar ferramentas aos membros da comunidade para que tenham autonomia nesse movimento de busca. Por essa razão, optamos pela participação da comunidade na elaboração do conteúdo e no desenvolvimento do curso, através da doação de documentos e fotos, de pesquisa pelos temas que consideravam mais relevantes, das entrevistas concedidas para uso didático e posteriormente documental, pelos questionários respondidos sobre $\mathrm{o}$ andamento das atividades e das aulas. O projeto Italiano como Herança contribuiu e ainda contribui significativamente para esse movimento emancipatório da comunidade no tocante à preservação de traços culturais de da LH na comunidade de Pedrinhas Paulista.

\section{Considerações finais}

Nosso projeto de pesquisa nos permitiu observar e reconhecer a importância dos parâmetros da Pedagogia Pós-Método (KUMARAVADIVELU, 2003, 2006), que propõem um professor reflexivo, produtor de suas próprias teorias e autor de suas próprias práticas, atento ao processo de ensino-aprendizagem, estabelecendo uma relação dialógica entre teoria e prática e mudando suas estratégias de ensinar ao observar as estratégias de aprender dos alunos e suas necessidades (parâmetro da praticidade); ressaltam a importância de o material didático ser sensível ao contexto histórico e sociocultural da comunidade a que pertencem os alunos (parâmetro da particularidade); propõem o estímulo à autonomia dos aprendizes e da comunidade, de modo que possam promover ações que possibilitem a preservação da língua e da cultura (parâmetro da possibilidade).

A análise do processo de produção do material didático para o curso Italiano como Herança nos possibilitou constatar, em primeiro lugar, que histórias de vida (MEIHY; HOLANDA, 2015) de membros da comunidade podem se constituir em uma rica matéria-prima para elaboração de material didático para o ensino de uma $\mathrm{LH}$ e, em segundo lugar, que o próprio ato de colher narrativas orais na língua de herança contribui para que a própria comunidade se envolva no planejamento de ações para a revitalização linguística e cultural de que são herdeiros.

\section{AGRADECIMENTOS: CAPES e CNPq}




\section{REFERÊNCIAS}

ALMEIDA FILHO, J. C. P. Dimensões comunicativas no ensino de línguas. 3 ed. Campinas: Pontes, 2002.

BAUMAN, Z. Identidade: entrevista a Benedetto Vecchi. Rio de Janeiro: Jorge Zahar Editor, 2005.

BORGES PEREIRA, J. B. Italianos no mundo rural. 2 ed. São Paulo: Edusp, 2002.

BORNETO, C. S. C'era una volta il metodo: tendenze attuali nella didattica delle lingue straniere. Roma: Carocci Editore, 1998.

CASTRO, G. M. Pedrinhas Paulista: memória e invenção. 2002. 184 f. Tese (Doutorado em Geografia Humana) - Faculdade de Filosofia, Letras e Ciências Humanas, Universidade de São Paulo, São Paulo, 2002.

FORNASIER, R. M. L. A produção de material didático para o ensino de italiano como língua de herança na perspectiva Pós-Método. 202 f. Dissertação (Mestrado) Faculdade de Filosofia, Letras e Ciências Humanas, Universidade de São Paulo, São Paulo, 2018.

GIDDENS, A. The consequences of modernity. Stanford: Stanford University Press, 1990.

HALL, E. The Silent Language. New York: Anchor Books, 1990.

HALL, S. Da diáspora: identidades e mediações culturais. Belo Horizonte: Editora UFMG, 2003.

HALL, S. A identidade cultural na pós-modernidade. 8 ed. Rio de Janeiro: DP\&A Editora, 2003.

HALL, S. Representation: cultural representation and signifying practices. London: Sages Publications Inc., 1997.

KUMARAVADIVELU, B. Language teacher education for a global society: a modular model for knowing, analyzing, recognizing, doing and seeing. New YorkLondon: Routledge, 2012.

KUMARAVADIVELU, B. Understanding language teaching: from method to postmethod. New Jersey: Lawrence Erlbaum Associates, 2006.

KUMARAVADIVELU, B. Beyond Methods: macrostrategies for Language Teaching. New Haven: Yale University Press, 2003.

KUMARAVADIVELU, B. Towards a postmethod pedagogy. TESOL Quarterly. Inverno 2001, v. 35, n. 4, p. 537-560, 2001.

LEFFA, V. J. Língua estrangeira. Ensino de aprendizagem. Pelotas: Educat, 2016. 
MEIHY, J.C.; HOLANDA, F. História oral: como fazer, como pensar. Editora Contexto: São Paulo, 2015.

MENDES, E. Vidas em português: perspectivas culturais e identitárias em contexto de português língua de herança. Platô, Cidade da Praia (Cabo Verde), v.1, p. 20-31, 2012.

ORTALE, F. L. A formação de uma professora de italiano como língua de herança: o Pós-Método como caminho para uma prática docente de autoria. 2016. $163 \mathrm{f}$. Tese (Livre-Docência em Língua Italiana) - Faculdade de Filosofia, Letras e Ciências Humanas, Universidade de São Paulo, São Paulo, 2016.

ORTALE, F. L.; CORRIAS, V.; FORNASIER, R. M. L. Desafios no ensino da língua de herança: o italiano em Pedrinhas Paulista. Revista Letras Raras, Campina Grande, v. 6, n. 2, p. 72-86, 2017.

\section{SAMOVAR L. A.; PORTER, R. E.; MCDANIEL E. R. Intercultural}

Communication: a Reader. 13 ed. Stamford: Wadsworth Gengage Learning, 2010.

SCALZO, R. A. L'approccio comunicativo. Oltre la competenza comunicativa. In: BORNETO, C. S. C'era una volta il metodo: tendenze attuali nella didattica delle lingue straniere. Roma: Carocci Editore, 1998. p. 140-171.

SOARES, S. M. de C. Português Língua de Herança: da Teoria à Prática. 2012. 120 f. Dissertação (Maestrado em Letras) - Faculdade de Letras, Universidade do Porto, Porto, 2012.

SOBRERO, A.; MIGLIETTA, A. Introduzione alla linguistica italiana. Roma-Bari: Laterza, 2005.

SOUZA A.; BARRADAS O. Português como Língua de Herança: Políticas Linguísticas na Inglaterra. Revista SIPLE, Brasília, maio 2013, ed. 6, ano 4, n.1, 2013.

\section{Como referenciar este artigo}

FORNASIER, Rosângela Maria Laurindo.; ORTALE, Fernanda Landucci.; CORRIAS, Vinicio. Os aspectos culturais na elaboração de material didático para o ensino de língua de herança: estudo de caso. Rev. EntreLínguas, Araraquara, v.4, n.1, p. 81-96, jan./jun., 2018. E-ISSN: 2447-3529. DOI: 10.29051/rel.v4.n1.2018.10993

Submetido em: 31/01/2018

Aprovado em: 17/03/2018 